\title{
Analysis of E-Consumer Behaviour - Selected Findings from an Analysis of Czech E-Shops and their Customers during the Global Pandemic
}

\author{
Frantisek Pollak ${ }^{1, *}$, Michal Konecny ${ }^{1}$ \\ ${ }^{1}$ Institute of Technology and Business, Faculty of Corporate Strategy, Okruzni 517/10, 37001 Ceske Budejovice, Czech Republic
}

\begin{abstract}
The study presented in this contribution deals with the issue of using modern methods of data collection for the purposes of analysing consumer behaviour. Professional literature as well as business practice offer us an enormous number of approaches, traditional or innovative, with which it is possible to obtain and then evaluate data in order to understand specific patterns of consumer behaviour. Following on from our previous research in the field, we have applied a method of collecting and evaluating customers e-data in real time. As a source of data, we used the virtual social network Facebook. As a sample we selected customers of the five largest e-shops operated in the Czech Republic. On a sample of more than one and a half million users we monitored the $\mathrm{B} 2 \mathrm{C}$ communication of e-shops and subsequently the $\mathrm{C} 2 \mathrm{~B}$ Facebook interaction of their customers during the lockdown caused by the COVID-19 pandemic. In the observed period we analysed hundreds of thousands of interactions and then outlined basic trends and specific characteristics of consumer behaviour suitable for further research. The selected findings resulting from the implemented analyses contribute to the creation of a knowledge base of a qualitative nature, which can help to define research goals in the future process of examining the effects of the pandemic on various aspects of business.
\end{abstract}

Keywords: e-commerce; Facebook; COVID-19; customer interactions; consumer behaviour; lockdown; pandemic

\section{Introduction}

The application of innovative practices and the management of innovation in general, within the context of the continuous development of ICT, has been an important topic of business practice for several decades [1]. The advantage of using ICT in companies lies mainly in the possibility of more efficient optimization of the supply-customer chain and also in the possibility of a better approach to customers themselves [2]. E-commerce is increasingly becoming an integral part of the core business of most businesses operating in an increasingly globalized market [3]. Under standard conditions, the transition to e-commerce is a continuous process, necessary in the long run, but mostly not yet conditioning the very existence of companies in the short term. Due to the unusual situation in the global market, namely the pandemic caused by the COVID-19 virus, companies suddenly had to reconsider their position on applying e-commerce tools to their portfolios, as countries across the Western market began to close their economies to slow the spread of the pandemic. Analysts estimate that the damage to the global economy may be in the region of $2-4 \%$ of world GDP [4]. The disease, which broke out in the Chinese city of Wuhan in December 2019, probably due to the consumption of an unidentified animal [5], shows no signs of slowing down and has claimed more than a million lives to date [6]. The aim of the study is to present partial qualitative results of currently implemented comprehensive research into selected characteristics of consumer behaviour and its changes during the first COVID-19 lockdown. Following on from our previous research in the field, we have applied a method of collecting and evaluating data in real time. On the sample of more than one and a half million Facebook users / customers of the five biggest e-shops on the Czech market, we monitored the B2C communication of the aforementioned e-shops and subsequently the $\mathrm{C} 2 \mathrm{~B}$ interaction of their user groups during the first lockdown caused by the COVID-19 pandemic. In the observed period, which created an almost model situation for our research, we analysed hundreds of thousands of users' interactions and then outlined specific characteristics of consumer behaviour suitable for further research. The selected findings resulting from the implemented analyses contribute to the creation of a knowledge base of a qualitative nature, which should help to expand general knowledge in the field of innovation in management, crisis communication and marketing approaches.

\footnotetext{
*Corresponding author: frantisek.pollak@mail.vstecb.cz
} 


\subsection{Basic definition of key terms and contexts}

\subsubsection{E-commerce}

As far as practice is concerned, there is often confusion in the identification of the terms e-commerce and e-business. One point of view is that the two terms are synonymous because the two terms include business processes that are carried out electronically, in particular via the Internet. Another point of view is that the two concepts are perceived differently because e-commerce is a subset of e-business [7]. According to Turcu and Feraru [8], e-commerce and e-business are somewhat similar and also have some of the same characteristics in that both processes seek to increase profits, reduce costs and improve business processes to generate added value for products and services. In general, it can be stated that e-commerce is part of a broad portfolio of e-business tools. Let us now look in more detail at the issue of e-commerce, specifically its benefits for businesses, consumers and society as a whole.

Benefits of e-commerce for organizations:

- $\quad$ organizations have the opportunity to expand their local markets to national and international markets, which includes minimal capital expenditure, and also have the ability to easily and quickly find a number of consumers, suppliers or the best business partners around the world;

- lower costs for organizations in terms of acquiring, processing, transforming, distributing, storing or analyzing information;

- $\quad$ organizations have the opportunity to reduce costs and inventory within the supply chain;

- $\quad$ organizations have the possibility of lower capital expenditures on business;

- communication costs for organizations are lower due to the use of the Internet, which is cheaper;

- formation of process-organizational systems in organizations;

- other benefits include faster access to information, shorter time, better productivity, improved customer service, and a wide selection of business partners [9].

Benefits of e-commerce for consumers:

- the opportunity to buy and secure transactions at any time, any day and also from anywhere;

- $\quad$ the opportunity to compare prices faster and to buy at lower prices;

- $\quad$ fast delivery;

- much wider choice of sellers who provide goods and services;

- the opportunity to participate in virtual auctions;

- the opportunity to take advantage of discounts due to increased competition;

- the opportunity to obtain important and detailed information about products and services at any time and from any place;

- connection to other consumers, through which they have the opportunity to exchange experiences and opinions about different products or services within virtual communities [9].

Benefits of e-commerce for society:

- the possibility of working within one place or from home, which eliminates the need to commute to work on a daily basis, which also leads to a reduction in traffic on the roads and also to air pollution;

- the possibility to buy larger quantities in case of discounts;

- the possibility of using products or services, hitherto unknown or inaccessible to customers from less developed countries, which gives them a considerable ability to assert themselves, especially the possibility of education or professional growth;

- $\quad$ simpler, faster, qualitatively better and lower-cost provision of public services, irrespective of whether it concerns social services, healthcare services or education [10].

Rajib [11] deals with the main aspects of e-commerce, to a large extent influencing the functioning of e-business, which need to be considered before the e-commerce itself can be created. The first, very important features are flexibility and adaptability. Before an e-shop itself is created, the operator of the online store should be sure that the website of the store will be displayed correctly to each internet user and that modern technological elements will be used in creating the online store. In the event that outdated forms or outdated visualizations are used, the website may not be of interest to 
Internet users, which could cause a decrease in traffic to the website. Rajib [11] cites ease and instinctive use as another important element in creating an online store website. He considers it unnecessary to use too many functions, which are complicated, and which are not necessary for the Internet user, respectively does not know how to use them. Of course, the price of creating an online store is also determined by the complexity of the functions. Many beginning e-commerce website owners do not have the capital to consider the more complex features of a website. Within this context, the most sensible approach is to use a smaller budget to start with and to then add additional features to the online store over time. According to the author, the most important feature is security, which is based on the fact that customers are required to provide their personal data when making a purchase. In the event that a customer registers a leak of information to a third party, they will most likely stop using the website of the online store and never purchase anything through it again. Also of importance is a high quality payment system. The online store must be able to accept multiple customer payments at once. The proven and most used payment systems in the world are Internet banking, payments via credit or debit card, or the PayPal system [12-13].

\subsubsection{M-commerce}

Brzozowska and Bubel [14] argue that e-business is mainly a process of managing an organization with the help of mobile information and communication technologies (ICT), or through their direct use. Prihastomo et al. [15] are of the opinion that today we live in a modern age in which mobile phone technology is already relatively advanced. M-business is created by activities, processes or applications implemented or supported by mobile technologies. Gála [16] highlights several differences between $\mathrm{m}$-commerce and e-commerce. These differences are:

- a mobile device is independent of place, respectively location;

- a mobile device together with the applications on it have a reach anytime and anywhere, unlike e-commerce, which requires an Internet connection from a specific place, i.e. they differ in the scope of reach;

- a mobile device is much cheaper and ultimately provides better accessibility for consumers compared to computers or laptops;

- the ability to operate a mobile device immediately without the need to instal software;

- within m-commerce, immediate identification of the user on the basis of SIM card, which is registered in a specific name or to a specific subject;

- the possibility of one-to-one marketing via mobile devices, which from the merchant's point of view means that they are in direct contact with their customers;

- knowing the immediate location of a mobile device user is appropriate from a marketing point of view, specifically due to the implementation or targeting of its various forms to the user.

A study conducted by the Association for Electronic Commerce (APEK) found that m-commerce is on the rise in the Czech Republic and that young people in particular make purchases via mobile devices. According to this study, at least one purchase was made on a smartphone or tablet by half the people questioned. As part of its current research, APEK asked consumers about their experience with mobile shopping. Jan Vetýška, executive director of APEK, is quoted as saying that " $50 \%$ of respondents made at least one purchase using a smartphone or tablet". This is $8 \%$ more than in 2017. The fact that shopping via mobile technology is most popular with the youngest consumers is not considered a big surprise. Within the age category $15-24$ years, $74 \%$ of respondents bought via smartphone or tablet. Within the age category over 55 years, only $21 \%$ of respondents confirmed their experience with this form of shopping. Vetýška is further quoted as saying "shopping via mobile devices is growing steadily. However, it must be said that its popularity in the Czech Republic and Europe in general is still very low compared to, for example, Asia". For historical reasons, the inhabitants of Asian countries often jumped from owning a computer directly to a smartphone, therefore the vast majority of orders in this important region are made using a mobile device. However, Czechs still place the majority of their orders via a computer or laptop. Mobile phones are also used by customers when shopping in brick-and-mortar stores. $39 \%$ of respondents confirmed that they occasionally use their smartphone to compare the prices of an online store with those in the brick-and-mortar store they are currently in where they are viewing the product. In exceptional cases, another $25 \%$ of respondents consult their smartphone in this way. However, customers behave similarly in relation to e-shops. $22 \%$ of respondents, when asked how mobile devices had changed their shopping behaviour, answered that they search for and compare goods in online stores on their mobile phones but choose a computer to process the order. In answer to the same question, $29 \%$ of respondents said that they search for information about goods or services more often through these handy devices, and $23 \%$ of respondents answered that they search for ratings or reviews from other users more than in the past. As part of the global trend, we can continue to see the growing importance of mobile sales. For this reason, too, e-shops are directing their investments to the development of responsive websites and their own sales applications. Nevertheless, it is not possible in the near future to expect similar dominance in the Czech Republic or even in Europe as can be seen in the eastern markets [17]. 
According to a study carried out by Worldpay payment technology, m-commerce will overtake computer purchases by 2023. As for German consumers, they are advocates of convenience and this is reflected in the way they do business. Mobile trading is still growing and is becoming the most popular shopping channel. Based on Worldpay payment technology data, we can expect the volume of m-commerce to reach EUR 44.3 billion by 2022, with a $16 \%$ annual increase. Based on calculations, Germany aims to become the world's sixth largest e-commerce market by 2022 . In its Global Payments Report 2018, Worldpay also cites electronic invoicing as the fastest growing payment method for German consumers. By 2022, the market share of e-invoicing could triple, making it the most popular online payment method. The increase in popularity is also visible in e-wallets (11\% annual increase), which puts them ahead of bank transfers, credit and debit cards. With the introduction of PSD2 (Payment Services Directive), the European Union's second directive on payment services in Europe, bank transfers could regain popularity during 2020, depending on how open banking solutions are adopted across the continent. The Worldpay study found that m-commerce accounts for $\$ 1.14$ trillion in global e-commerce sales and that global mobile commerce will grow by $19 \%$ by 2023 . By 2022 , growth is expected in China ( $€ 1.03$ trillion), the US ( $€ 320$ billion), the United Kingdom ( $€ 100$ billion), France ( $€ 54.5$ billion), India ( $€ 48$ billion) and Germany ( $€ 44$ billion), which are among the world's largest m-commerce markets [18]. A study conducted by PayPal, a global market research and consulting firm, found that consumers were more likely to buy smartphones than ever before, but there was still an interest in keeping their mobile business safe. A global study of 22,000 consumers of all ages found that up to $80 \%$ of consumers made a smartphone purchase, but in e-commerce, only $63 \%$ of organizations are optimized to receive mobile payments. "This is a big gap in businesses that are missing out by not taking advantage of the explosive growth of m-commerce," PayPal said in a statement. "Businesses need to offer a mobile-optimized experience if they are interested in attracting and retaining younger consumers, such as Gen $\mathrm{Z}$ and Gen Y." Giving priority to mobile phones could be a priority. The survey found that the main reason for the consumer to refrain from buying through m-commerce was that the trader could not provide them with the method of payment that they preferred. As a result, $21 \%$ of respondents stated that they therefore abandoned the purchase. Other key findings include the following:

- $\quad 72 \%$ of consumers in the US use a smartphone for online payments, but only $57 \%$ of organizations say they offer optimization for mobile devices. This is the second lowest value in all the countries surveyed.

- $\quad 48 \%$ of women prefer to buy via mobile device, for men it is $39 \%$. $19 \%$ of women shop via their mobile device at work, compared to $26 \%$ for men.

- The supply and demand for m-commerce is in line between traders and consumers, with 1 in 3 (women and men) in both categories stating that they use m-commerce.

- Facebook, Instagram and WhatsApp are among the most widely used m-commerce platforms worldwide (35\% of respondents are Facebook-owned users).

- $\quad 87 \%$ of brick-and-mortar merchants received a contactless payment, with $50 \%$ of these payments made via smartphone.

- India is a leader in the use of m-commerce, with $70 \%$ of consumers preferring $\mathrm{m}$-commerce purchases and $81 \%$ of retailers optimized for m-commerce.

- With $83 \%$, Italy is the top European market for consumers shopping online via smartphone, with $65 \%$ of Italian organizations claiming they have a mobile-optimized website or application.

In terms of trust and security, $51 \%$ of respondents worldwide are less likely to buy via mobile technology due to concerns about their security. In some countries, the percentage is lower. An example is Japan, where only $28 \%$ of respondents said they were less likely to buy via mobile technology due to security concerns. The biggest security concerns for m-commerce are in the UK (64\%), Australia $(63 \%)$ and the US $(58 \%)$. This is then passed on to retailers, with $20 \%$ of them citing consumer safety concerns as a reason for their reluctance to optimize for m-commerce. In a separate survey of holiday purchases in the US and Canada, AdColony [19] found that a mobile phone is considered as secure as a desktop computer. As part of AdColony's results regarding the purchase of gifts through m-commerce in cooperation with PayPal, focusing on the overall participation in m-commerce, it was found that $81 \%$ of respondents bought gifts via mobile phone. $45 \%$ of respondents said that they shop regularly via smartphone.

Other findings from the AdColony [19] survey:

- consumers bought various types of goods and services through m-commerce, whether they were books, event tickets or travel. Through m-commerce, the most purchased were clothes (43\%) or household goods (20\%);

- more than half of the respondents stated that they would never buy anything through a mobile device if they bought directly from advertising. However, if the product were relevant to them, $71 \%$ of respondents said they would buy the product;

- if the consumer visits the store, they will not make an online purchase unless they come across a cheaper price or if the store does not have the given size or colour of the item; 
- the importance of mobile devices when shopping was mentioned by $61 \%$ of respondents;

- mobile phones are used by consumers in various ways, but they are mostly used to find out competitors prices $(55 \%)$ or to obtain discounts $(46 \%)$.

In this first part of the study, we presented the results of desk research on the issue of e-commerce in order to approach the knowledge base of the analysed issues. Having done so, it is appropriate to undertake a deeper examination of the selected contexts.

\section{Methodology}

The aim of the study is to present partial qualitative results of currently implemented comprehensive research into selected characteristics of consumer behaviour and its changes during the first COVID-19 lockdown. This follows up on the methodology that we designed and subsequently implemented as part of research into the user activity of customers of SMEs [21]. The research was carried out in 2015. For the purpose of describing changes in consumer behaviour trends, it is used as a reference for the presented analysis.

The first step in the methodology used is to define the object of research, in this case the five largest e-commerce companies operating on the Czech market according Journal E-Commerce Bridge 2019 rankings [20]. The journal ranked the subjects on the basis of traffic on their websites. In the case of the e-shops, traffic together with turnover is the most relevant indicator of activity.

From the point of view of the research file, we focused on Czech customers who buy through e-shops. As for the research sample, it consisted of customers who are also fans of the official profiles of the selected e-commerce companies on the social network Facebook. In terms of numbers, it concerned a sample of 1,594,180 users.

From the point of the observed period, we collected data during the first COVID-19 lockdown from 12th March to 17th May 2020. Due to the fact that in the observed period e-shops represented one of the few or only alternatives for the purchase of goods and services, as most traditional infrastructure was closed, it can be said that model conditions for complex research were created.

From the point of view of the monitored parameters, the main focus was monitoring the timing and the number of posts, subsequently the number and types of interactions in which the users responded to the posts. In other words, we monitored the B2C Facebook e-marketing communication activities of the selected subjects and the C2B feedback (Like, Comment and/or Share) in predefined time frames. For the purpose of data unification and with the aim of in-depth analysis, a time frame of 24 hours was set for subtracting the frequency of interactions per published post on the subject's profile. After this time, we subtracted the final number for each of the observed posts interactions. It is known from empirical practice that the dominant number of interactions is recorded immediately after the publication of the post. Subsequently, post durability is reduced, as it is replaced or literally displaced by new contributions and content. The findings are therefore formulated as the number of interactions in relation to posts published on a particular day in a model week, although a particular interaction may have occurred within 24 hours of publication. As mentioned above, the dominant number of interactions occurs immediately; in any case, it is possible to view this methodological sequence as a partial limitation of the study. Using available resources and taking into account the quantity of data, we considered this limitation acceptable.

In this phase of the research, the data were evaluated by descriptive statistics, the basic trends visualized, compared with the reference values of research carried out in the past, and subsequently discussed in order to identify the basic qualitative findings for subsequent in-depth research. It is necessary to note that for the purposes of the research, the subjects were not compared with each other, as the aim of the research was not to optimize the processes of a particular company, but to design industry-wide indicators through relevant companies.

During the observed period from $12^{\text {th }}$ March to $17^{\text {th }}$ May 2020, we analysed hundreds of thousands of users' interactions and then outlined specific characteristics of consumer behaviour suitable for further research. The research provided comprehensive findings, of which we selected specific ones resulting from the implemented analyses, in order to contribute to the creation of a knowledge base of a qualitative nature, which should help to expand knowledge in the field of innovation in management, crisis communication and marketing approaches.

\section{Results and Discussion}

The specific situation created a model environment for examining the specifics of consumer behaviour. As previously stated in the introduction, e-commerce brings companies a wide range of advantages over traditional forms of trading. This includes, among other things, the advantage of feedback in real time. Academics and practitioners alike are being more and more confronted with the fact that the value of a company no longer lies in its economic indicators, but in its benefits for society. Customers transform themselves from nameless consumers into active followers, into communities that have their own dynamics, express assertive feedback, and largely determine the value of an organization through their attitudes, especially if it concerns a publicly traded organization. Examples of such organizations are the showcases 
of Western economies such as Apple or Tesla. At this point, the question has to be asked, how does the collapse of the traditional consumer supply chain, forced by the lockdown of the economy, affect the interaction of these active and assertive communities?

In the following table we present the basic indicators of the activity of the monitored companies, according to the Facebook profiles of the five largest operators of e-commerce services in the Czech Republic [20], namely: Alza.cz, Mall.cz, CZC.cz, Aukro.cz and Lidl ČR on the basis of the accumulated number of posts during the monitored period. These activities are followed up by the basic numbers of user interactions in relation to those activities, as calculated through descriptive statistics. The results are as follows:

Table 1. Indicators of overall activity

\begin{tabular}{|l|c|c|c|c|c|}
\hline & $\begin{array}{c}\text { Number of posts } \\
\text { (n) }\end{array}$ & $\begin{array}{c}\text { Number of likes } \\
(\mathbf{n})\end{array}$ & $\begin{array}{c}\text { Number of comments } \\
\text { (n) }\end{array}$ & $\begin{array}{c}\text { Number of shares } \\
\text { (n) }\end{array}$ & $\begin{array}{c}\text { Number of days. } \\
\text { (n) }\end{array}$ \\
\hline SUM & 689 & 349,315 & 399,243 & 72,904 & 67 \\
\hline Daily Max & 18 & 28,082 & 96,261 & 11,559 & 67 \\
\hline Daily Min & 4 & 391 & 34 & 18 & 67 \\
\hline Daily Average & 10 & 5,214 & 5,959 & 1,088 & 67 \\
\hline Daily Modus & 11 & - & - & 42 & 67 \\
\hline Daily Median & 11 & 3,556 & 924 & 325 & 67 \\
\hline \multicolumn{7}{|r|}{ Total fans 1,594,180 } \\
\hline
\end{tabular}

Source: Authors.

During the monitored period of 67 days, more than 800,000 user interactions were recorded for a total of 689 posts/contributions published on the profiles of subjects. If the total number of fans of the subjects is taken into account, it can be said that the groups are relatively active.

During the monitored period, a total of almost 30,000 likes, 100,000 comments and more than 11,500 shares were cumulatively recorded as a maximum value in one day.

These are relatively high numbers, in particular when taking into consideration that the proportions correspond approximately to the nature and value of the type of interaction as we know them from previous reference research carried out in the past [21]. The following visualizations bring into picture the interactions during the reference model week and model week during the COVID-19 lockdown:

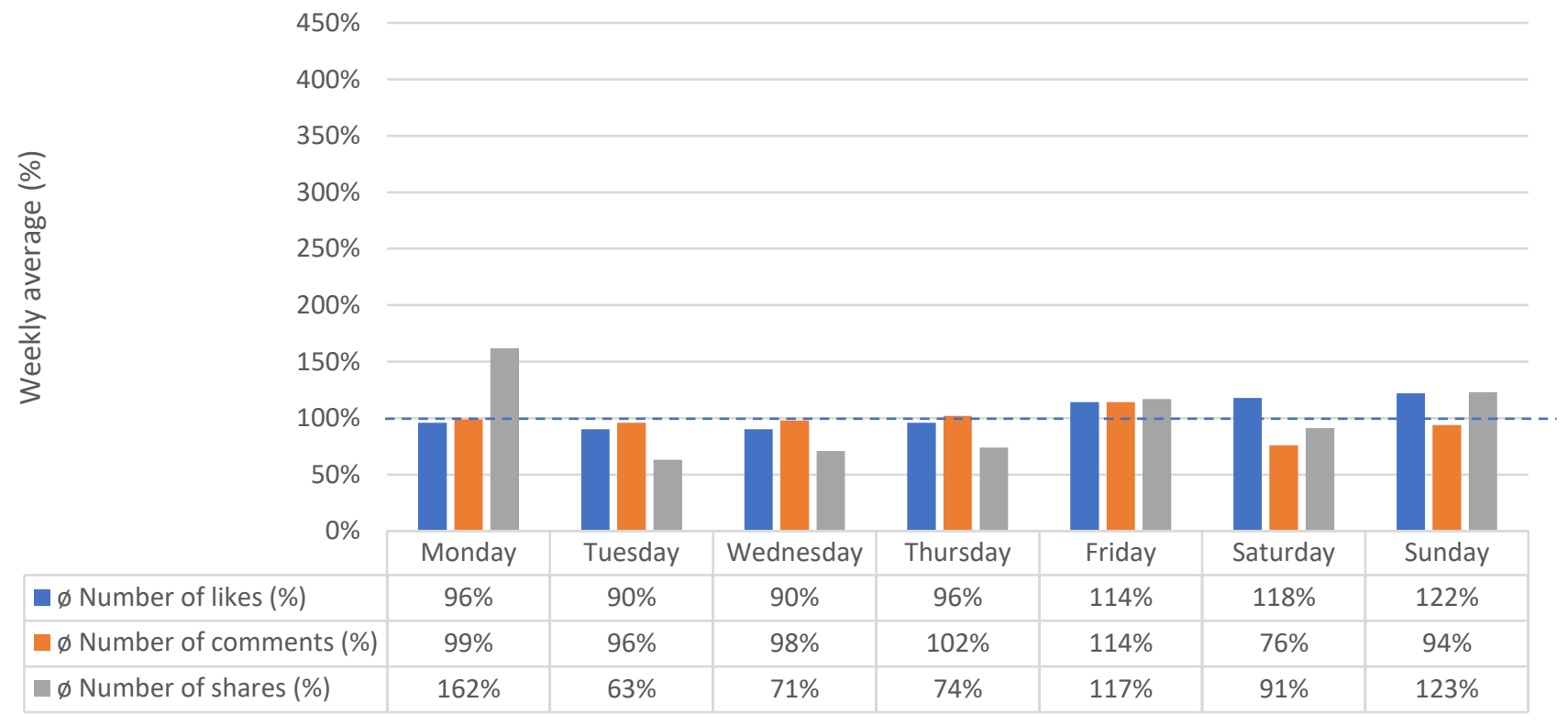

Figure 1. Interactions during the reference model week

Source: [21].

Legend: Number of posts was not monitored during the reference period

As can be seen in Figure 1, in the previous research we identified that, from the point of view of the model week, user interactions were distributed relatively evenly. From the point of view of the maximum interaction "share", we recorded the value of maximum relative abundance on the first day of the working week. In terms of "like" and "comment" interactions, the values during the week oscillated around the average. Above-average values were subsequently recorded 
at the end of the working week and during the weekend. With a certain degree of abstraction, it can be stated that, under normal conditions, the activity of users at the beginning and end of the working week is partly related to the gradual increase or decrease in work commitment. Subsequently, during the weekend, users focus their online activities on B2C communication in its simplest form, specifically by liking marketing communications on the fan pages of the companies.

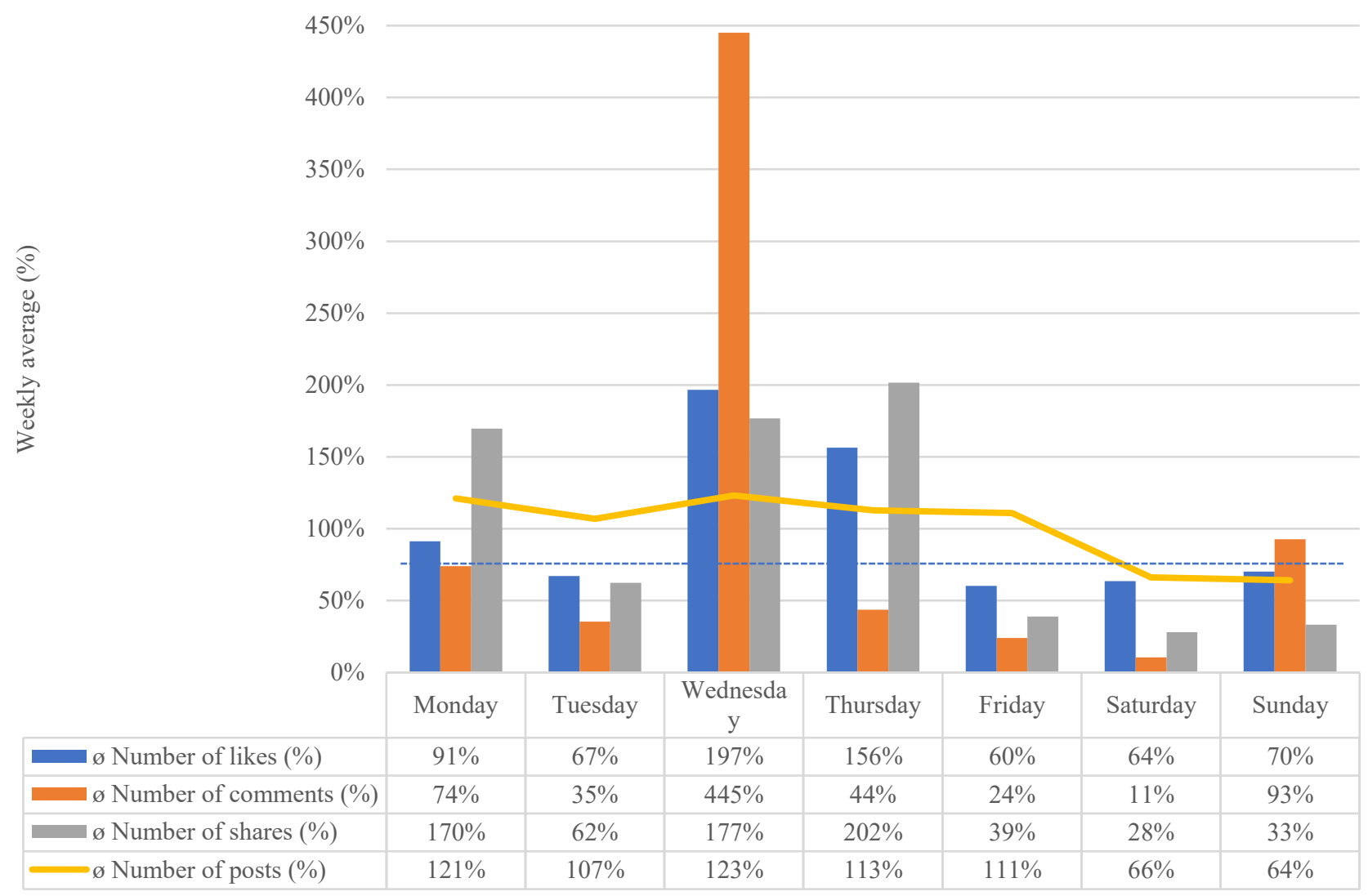

Figure 2. Interactions during the model week - COVID-19 lockdown

Source: Authors.

Figure 2 shows selected characteristics of consumer behaviour in the form of user group interactions in relation to the marketing communications of the monitored e-shops. The recorded data was classified during the observed period on the basis of the days of the week, in order to model the cumulative relative numbers of the individual groups of user interactions over time. On the $\mathrm{x}$-axis are both $\mathrm{B} 2 \mathrm{C}$ communications in the form of the number of contributions/posts of the companies, as well as the feedback in the form of interactions to these posts, i.e. the $\mathrm{C} 2 \mathrm{~B}$ communications of customers with the e-shops. On the $y$-axis is an indicator in the form of a weekly average. It presents the arithmetic mean of the individual cumulative frequencies of that interaction during the observed period. For better orientation, the weekly average of interactions is marked with a dashed blue line.

As previously mentioned, these are the partial results of a comprehensive study. As a result, in the discussion of the findings, due to the scope limitations of the contribution, the focus is only on the selected characteristics. A closer examination of how the sample behaved during lockdown shows that on the first working day of the week, a relatively major increase in the number of marketing communications from the companies was recorded. In terms of numbers, this is a $21 \%$ increase compared to the measured average. In terms of customer interactions, the average relatively cumulative number of interactions in the form of likes and comments is only below average. On the other hand, interactions in the form of shares, which on the basis of our research are evaluated as the most valuable, achieve a value significantly aboveaverage. Specifically, this is the third highest value indicated during the model week. As it is a specific interaction traditionally caused by the marketing activity of a company, it can be partly attributed to the increased Monday activity of the companies, which keep their customers engaged in the form of various competitions and games. At the same time, it is known that this user activity is not enforceable in terms of expected numbers. Therefore, its abundance can be affected by both character and timing. It can be deduced from the data that users are looking for a way to monetize their "efforts" after the weekend. Simple interactions in the form of comments and likes are likely to be replaced by more targeted online activity. How this is reflected in their work commitment and performance is questionable. The second working day of the week has the character of below-average indicators on the part of both companies and their customers. Each of the monitored parameters gradually, in some cases significantly, decreases. It is possible to assume users increased focus on their work and activities outside the online environment. However, to confirm this it is necessary to examine user interactions in terms of hours within the model day. The third working day of the model week during the lockdown, is characterized by a large increase in user interactions to only an above-average number of posts on the profiles of the 
monitored e-shops. The indicator "comments" achieves a value significantly above-average. It is possible to assume that users use this form of interaction for the purpose of socialization in the middle of the working week. It is also possible to assume that this indicator has a cumulative nature from the point of view of trends, when in the days preceding and following the monitored parameter, the monitored period is cut. Despite the absence of more complex data, it is therefore possible to indicate the trend of so-called Wednesday comments. We see a similar, although not so significant, trend in the case of interactions in the form of likes. Thursday is marked by the second highest average activity of the companies and well above-average activity of users in the form of likes and shares. The sharing parameter reaches its weekly maximum, where it exceeds the weekly average by more than two times. After Wednesday's maximum, the comment parameter records only trace values at the level of $44 \%$ of the weekly average. The sharing parameter reaches its weekly maximum. The question of labour productivity during the model lockdown week therefore opens up again, which is something we will address as part of our continuous research into the issue in the near future. On Friday, user interactions fall sharply for all the monitored parameters, whereby only the likes parameter reaches a level higher than $50 \%$ of its weekly average. At the same time, from the point of view of positions with the character of marketing communications published on the profiles of the monitored companies, this is an above-average saturated day. Due to other measured values, it is possible to classify this day in terms of "weekend" interactions, whereby users are most likely to dedicate their time to life outside the online world. Respectively, their stay in the online space is greatly reduced. The mean for the monitored indicators is below-average for Saturday and Sunday. Saturday in particular is marked as an "offline" day, where both the companies and their customers have their attention drawn in a different direction. From the point of view of the values measured before and during the pandemic, it is possible to express only statements in the form of research questions. Specifically, how exactly did the pandemic affect e-consumer behaviour? How negatively did the lockdown affect labour productivity? Were users distracted by activities unrelated to their work during home office? If so, to what extent? Our past research [21] indicates certain patterns of behaviour, but in the case of the presented research, the measured values for almost all parameters significantly exceed the original values, even though they basically confirm the trends we indicated from the pre-crisis period. The weekend is preferred for activities outside the online world, while the working week is the preferred time for various aspects and activities of e-consumer behaviour. The individual days of the week are significantly specific in terms of the expected interactions.

\section{Conclusion}

The global pandemic has severely disrupted traditional supplier-customer ties. During the 67 days of first lockdown caused by the new coronavirus, the market's attention shifted from one day to the next from offline to online. With the closure of brick-and-mortar stores (excluding stores selling daily consumer products and medicines), both providers and consumers of goods and services were forced to significantly modify their usual patterns of behaviour. It is a big surprise that the supply chain did not experience any significant problems within our sample. The best players on the market were able to adapt to the new conditions relatively quickly, which customers appreciated, and which was reflected in the considerable number of positive interactions. Consumer behaviour, and the specifics thereof, have also adapted to the situation. Past practice and empirical studies [22-24] have shown that some behavioural adaptations were temporary and consumer behaviour has reverted to its original state, but that other behavioural adaptations have become the new norm. It is therefore necessary to prepare for this challenge, to apply innovative procedures and methods to the usual routines and to confront this non-standard challenge. Evolutionary theory teaches us that the most adaptable, not necessarily the best will survive. As stated at the beginning of the study, the observed period created a model situation for our research. We analysed hundreds of thousands of users' interactions and then outlined specific characteristics of e-consumer behaviour suitable for further research. The selected findings resulting from the implemented analyses contribute to the creation of a knowledge base of a qualitative nature, which should help to expand knowledge in the field of innovation in management, crisis communication and marketing approaches. From the point of view of the limitations of the presented study, it is necessary to point out the fact that despite the significantly representative sample, the data presented in this partial study of the currently implemented comprehensive research are only of a qualitative nature. The findings and trends indicated and discussed in the study are based mainly on abstraction because there is still no relevant data that we can use as basic values for the pre- and post-crisis period. As part of the continuous research, we want to focus on monitoring trends during the second wave of COVID-19 and related measures with a lockdown nature, as well as analysing data in the coming period of economic recovery after the pandemic. Only then will it be possible to evaluate the research in terms of quantitative data, and thus formulate relevant findings for science and practice. In time, the ambition of the authors is to contribute to the development of a qualitative knowledge base for continuous research in the field.

\section{Acknowledgement}

This research was funded by the Technology Agency of the Czech Republic, Programme of ETA, Project Reg. No. TL 0200215- Digital Transformation for Business Model Innovations in Small and Medium Sized Enterprises in the Czech Republic. 


\section{References}

1. D. Chaffey, Digital marketing. London: Pearson (2015)

2. T. Mazzarov, SMEs engagement with e-commerce, e-business and e-marketing [online]. Available at: https://doi.org/10.1080/13215906.2015.1018400 (2015)

3. R. Madleňák, L. Madleňáková, Základy elektronického obchodovania [Basics of e-commerce]. Žilina: EDISvydavatel'stvo ŽU (2016)

4. S. Luo, K. P. Tsang, How Much of China and World GDP Has The Coronavirus Reduced? [online]. Available at: https://www.coronavirusandtheeconomy.com/ongoing-research/how-much-china-and-world-gdp-has-coronavirusreduced (2020)

5. Z. Wu, J. M. McGoogan, Characteristics of and important lessons from the coronavirus disease 2019 (COVID-19) outbreak in China: summary of a report of 72314 cases from the Chinese Center for Disease Control and Prevention. Jama. 323(13), 1239-1242 (2020)

6. World Health Organization, WHO Coronavirus Disease (COVID-19) Dashboard [online]. Available at: https://covid19.who.int (2020)

7. A. Khurana, Ebusiness vs. Ecommerce - Understanding the Difference: Ebusiness vs. Ecommerce [online]. Available at: https://www.thebalance.com/ebusiness-vs-ecommerce-1141573 (2016)

8. O. L. Turcu, A. Feraru, E-business - A Contemporary Realistic Form Of Successful Business. Economics Edition, "Vasile Alecsandri” University of Bacau, Faculty of Economic Sciences (2013)

9. D. Benešová, E-business v službách [E-business in services]. Bratislava: Vydavatel'stvo Ekonóm (2010)

10. M. Bodiš, Procesy elektronického obchodu [E-commerce processes]. Trendy v podnikaní. 4(2), 4-10 (2014)

11. R. Rajib, Learning more ecommerce and online business. Morrisville: Lulu Press, Inc. (2016)

12. R. Čiarniené, G. Stankevičiuté, Theoretical Framework of E-Business Competitiveness. Kaunas. Procedia-Social and Behavioral Sciences. 213, 734-739 (2015)

13. K. Bystrická, J. Jesenič, M. Tužinský, Internetový obchod [Eshop]. $2^{\text {nd }}$ ed. Bratislava: Wolters Kluwer (2016)

14. A. Brzozowska, D. Bubel, E-business as a new trend in the economy. International Conference of Communication, Management and Information Technology. Procedia Computer Science. 65, 1095-1104 (2015)

15. Y. Prihastomo, A. N. Hidayanto, H. Prabowo, M. Widjaja, The Key Success Factors in E-marketplace Implementation: A Systematic Literature Review. 2018 International Conference on Information Management and Technology (ICIMTech) (2018)

16. L. Gála, J. Pour, P. Toman, Podniková informatika: počitačové aplikace v podnikové a mezipodnikové praxi, technologie informačnich systémů, ř́zení a rozvoj podnikové informatiky [Business informatics: computer applications in business and intercompany practice, information systems technology, management and development of business informatics]. Praha: Grada Publishing, a.s., (2006)

17. P. Michl, Studie APEK: M-commerce v Česku roste, přes mobil nakupuji nejčastěji mladí [APEK study: M-commerce is growing in the Czech Republic, young people most often shop via mobile phones] [online]. Available at: https://www.focus-age.cz/m-journal/aktuality/studie-apek--m-commerce-v-cesku-roste--pres-mobil-nakupujinejcasteji-mladi_s288x14062.html (2018)

18. S. Steiger, Studie: M-Commerce überholt Desktop-Shopping bis 2023 [Study: M-Commerce will overtake desktop shopping by 2023]. [online]. Available at: https://www.ibusiness.de/akzuell/db/248674steiger_2.html (2019)

19. D. P. Clement, Study Finds 80\% of Consumers Shop on Smartphones, M-Commerce Gains [online]. Available at: https://multichannelmerchant.com/ecommerce/study-finds-80-consumers-shop-smartphones/ (2019)

20. Ecommerce Bridge, The largest e-shops in Slovakia and in the world in 2019 [online]. Available at: https://www.ecommercebridge.sk/najvacsie-e-shopy/ (2020)

21. F. Pollák, P. Dorčák, The effective use of facebook by small and medium-sized enterprises operating in Slovakia. Market. 28(1), 79-91 (2016)

22. P. Dorčák, P. Markovič, F. Pollák, Multifactor analysis of online reputation as a tool for enhancing competitiveness of subjects from automotive industry. Journal of Economics. 65(2), 173-186 (2017)

23. F. Pollák, P. Dorčák, P. Markovič, Reputation Management, Promotion and Marketing Communications, Umut Ayman and Anıl Kemal Kaya, London: IntechOpen. [online]. Available from: https://www.intechopen.com/books/promotion-and-marketing-communications/reputation-management (2019) 
24. J. Straková, P. Pártlová, J. Váchal, M. Vochozka, Excellent top manager system (ETMS) - Quality management tool tertiary education. Proceedings of the 29th International Business Information Management Association Conference - Education Excellence and Innovation Management through Vision 2020: From Regional Development Sustainability to Global Economic Growth. 1844-1852 (2017) 